\section{Repetitive Overseeding for Ecological Management of Grass Playing Fields}

\author{
Maria Gannett and Natalie Bray \\ School of Integrative Plant Science, Cornell University, Ithaca, NY 14853 \\ Joellen Lampman \\ New York State Integrated Pest Management, Voorheesville, NY 12186
}

Jennifer Lerner
Cornell Cooperative Extension, Brewster, NY 10509

Kathy Murray

Maine Department of Agriculture, Conservation, and Forestry, Augusta, ME 04330

\section{Victoria Wallace \\ University of Connecticut Extension, University of Connecticut, Norwich, CT 06360}

\section{Tamson Yeh \\ Cornell Cooperative Extension, Riverhead, NY 11901}

\author{
Mark Slavens \\ Research and Development, The Scotts Miracle-Gro Company, Marysville, \\ $\mathrm{OH} 43041$
}

\section{Grant L. Thompson \\ Department of Horticulture, Iowa State University, Ames, IA 50011}

\section{Jenny Kao-Kniffin \\ School of Integrative Plant Science, Cornell University, Ithaca, NY 14853}

Additional index words. broadleaf weeds, Lolium perenne, perennial ryegrass, pesticide-free, schools, turf

\begin{abstract}
Because of public concern about exposing children to pesticides, legislation restricting its use on school playing fields has increased. One way to manage weeds without chemical herbicides is overseeding or the practice of repetitively seeding with a rapidly germinating turfgrass species. Overseeding for broadleaf weed control was tested on eight fields in Central New York (CNY) for three seasons and 40 fields across the northeastern United States for two seasons. Half of each field was treated each season by overseeding Lolium perenne L. (perennial ryegrass) three to five times each season for a total of $731 \mathrm{~kg}$ seed/ha (15 lb per $\left.1000 \mathrm{ft}^{2}\right)$. Changes in the percent broadleaf weeds, grass, bare ground, soil moisture, Dark Green Color Index (DGCI) of grass cover, depth to soil compaction, and shear strength were measured after each treatment. The percent broadleaf weeds decreased and the percent grass cover increased due to overseeding in the Northeast fields, but not in CNY fields. Depth to compaction, percent soil moisture, and shear strength varied over time in the Northeast fields, and the percent bare ground, DGCI, and soil moisture varied over time in CNY fields. DGCI in the Northeast and soil compaction in CNY were affected by the interaction of overseeding $\times$ time. Although overseeding can be a beneficial weed management tool and affect other turf and soil traits in an integrated turf management program, monitoring environmental conditions and supporting field maintenance routines are critical weed management strategies for maintaining healthy turfgrass.
\end{abstract}

Concern about the potential health risks associated with continued exposure to pesticides is growing worldwide. Exposure to pesticides during childhood is of greater concern because children are at critical stages of cognitive development and their common behaviors, such as touching the face, ingesting soil, and crawling, increase their exposure in treated areas (Faustman et al., 2000). From 1998 to 2002, childhood pesticide exposure rates at schools increased yearly, and

$69 \%$ of cases were linked to school pesticide applications as opposed to pesticide drift from neighboring farms (Alarcon et al., 2005). Therefore, reducing use at schools could greatly reduce the risk of exposure for children.

In an attempt to reduce this risk, legislative action regulating and restricting pesticide use on school and public grounds has increased across the United States and abroad. As early as 1998, Denmark instituted a plan to phase out pesticides in public green spaces by 2003 (Larsen et al., 2004). In 2007, the State of Connecticut passed a law prohibiting the use of lawn care pesticides at schools and daycare centers, except with an emergency exemption (Connecticut General Assembly, 2009). In 2008, the Canadian Province of Ontario passed legislation restricting the use of pesticides for cosmetic purposes (Legislative Assembly of Ontario, 2008), and this was soon followed by several additional provinces (Canadian Nursery Landscape Association, 2017). In 2010, New York passed the "Child Safe Playing Fields Act" for all public and private schools and daycare centers, with restrictions similar to those used in Connecticut (New York State Department of Environmental Conservation, 2010). Within the United States, 10 states have enacted statewide integrated pest management requirements; however, only four of those states emphasize pesticide use as a last resort (Feldman and Hepting, 2007). Concern regarding childhood pesticide exposure is relevant, and legislation can help to reduce this risk; however, the adoption of pesticide-free field management techniques relies on a better understanding of the potential benefits and limitations of these techniques.

Schools and public grounds managers need to address a wide range of issues to maintain safe conditions on playing fields (referred to here as turfgrass). Regulations have decreased pesticide use, but they have also left facilities managers without many common tools to manage their athletic fields, play areas, and public grounds. Adapting management strategies to new regulations can be challenging and may require new tools and information specifically for school playing fields. Both plant and soil characteristics affect the quality and safety of the playing fields; in turn, many management strategies affect both plant and soil characteristics (Aldahir and McElroy, 2014; Waddington et al., 1997). Developing organic field management techniques that provide multifunctional benefits, such as simultaneous weed control, reduced surface hardness, improved soil health, less bare soil, and greater grass cover, are more desirable to managers than relying on singletarget strategies, especially considering the growing restrictions against pesticides.

Weed management without herbicides has been a particularly difficult task, but repetitive overseeding is one pesticide-free strategy that was recently developed to control weeds. Repetitive overseeding is the practice of supplementing a grass field with substantial amounts of turfgrass seeds to promote grass density and coverage. More than a decade of trials in Europe and North America have shown that overseeding can be an effective weed suppression strategy. Overseeding with Lolium perenne L. (perennial ryegrass) has been found to be effective for increasing turfgrass cover and, in some instances, decreasing weed pressure (Dahl Jensen et al., 2017; Miller and Henderson, 2012), especially for outcompeting Poa annua L. (annual bluegrass) (Aamlid et al., 2012). Overseeding ranges in effectiveness depending on the application frequency, rate, location, and climate conditions (Aamlid et al., 
2012; Elford et al., 2008; Larsen et al., 2004). The practice is less effective in cool and droughty conditions that decrease germination rates of broadcast turfgrass seed (Elford et al., 2008; Harper et al., 2016). Furthermore, varying moisture levels alter the dominant competitive weed species, affecting the outcome of overseeding for weed suppression (Aamlid et al., 2012; Elford et al., 2008; Harper et al., 2016). The effectiveness of overseeding increases with moderate trafficking to improve seed-soil contact (Chinery, 2009). However, not all soil disturbance has been found to be equal. Verticutting and overseeding alone can increase weed abundance, but the combination of vertical cutting, overseeding, and topdressing can increase turfgrass cover and decrease weed cover (Larsen et al., 2004).

Although the effectiveness of overseeding as a weed management tool for natural grass fields has been investigated in a variety of systems, large-scale field trials are lacking. Additionally, the effects of overseeding on multiple functional traits of turf and the underlying soil that affect safety, such as surface hardness and percent turfgrass cover, have not been studied. Our objectives were to test the overseeding strategy across a wide range of fields in three states of the United States and to measure the effects of the strategy on both turf and soil traits. We hypothesized that overseeding would decrease weed cover on school athletic fields with increasing efficacy over time as the number of applications increased. In addition to decreasing broadleaf weed cover, we hypothesized that overseeding would improve other turf and soil traits on the athletic fields by decreasing surface hardness and the percentage of bare ground.

\section{Materials and Methods}

Field setup. Our study was conducted on 48 typical high-use, relatively low-input, public school grass fields that serve athletic functions. These fields spanned 25 different locations across three states in the northeastern United States (New York, Maine, and

Received for publication 8 Sept. 2020. Accepted for publication 23 Nov. 2020.

Published online 7 January 2021.

We sincerely thank all the field managers who worked with us on this study and Lynn Johnson at the Cornell Statistical Consulting Unit for advice with the statistical analysis. We thank Marty Petrovic, Kyle Wickings, Frank Rossi, Carl Schimenti, Jeff Barlow, Joann Gruttadaurio, Lynn Braband, and Jennifer Grant for help with the study. We thank the United States Department of Agriculture, Crop Protection and Pest Management Program (award number 2014-70006-22633) and the New York State Turfgrass Association for funding to support the research project. We thank the Scotts company for donations of supplies for the fieldwork.

J.K.-K. is the corresponding author. E-mail: jtk57@ cornell.edu.

This is an open access article distributed under the CC BY-NC-ND license (https://creativecommons.org/ licenses/by-nc-nd/4.0/).
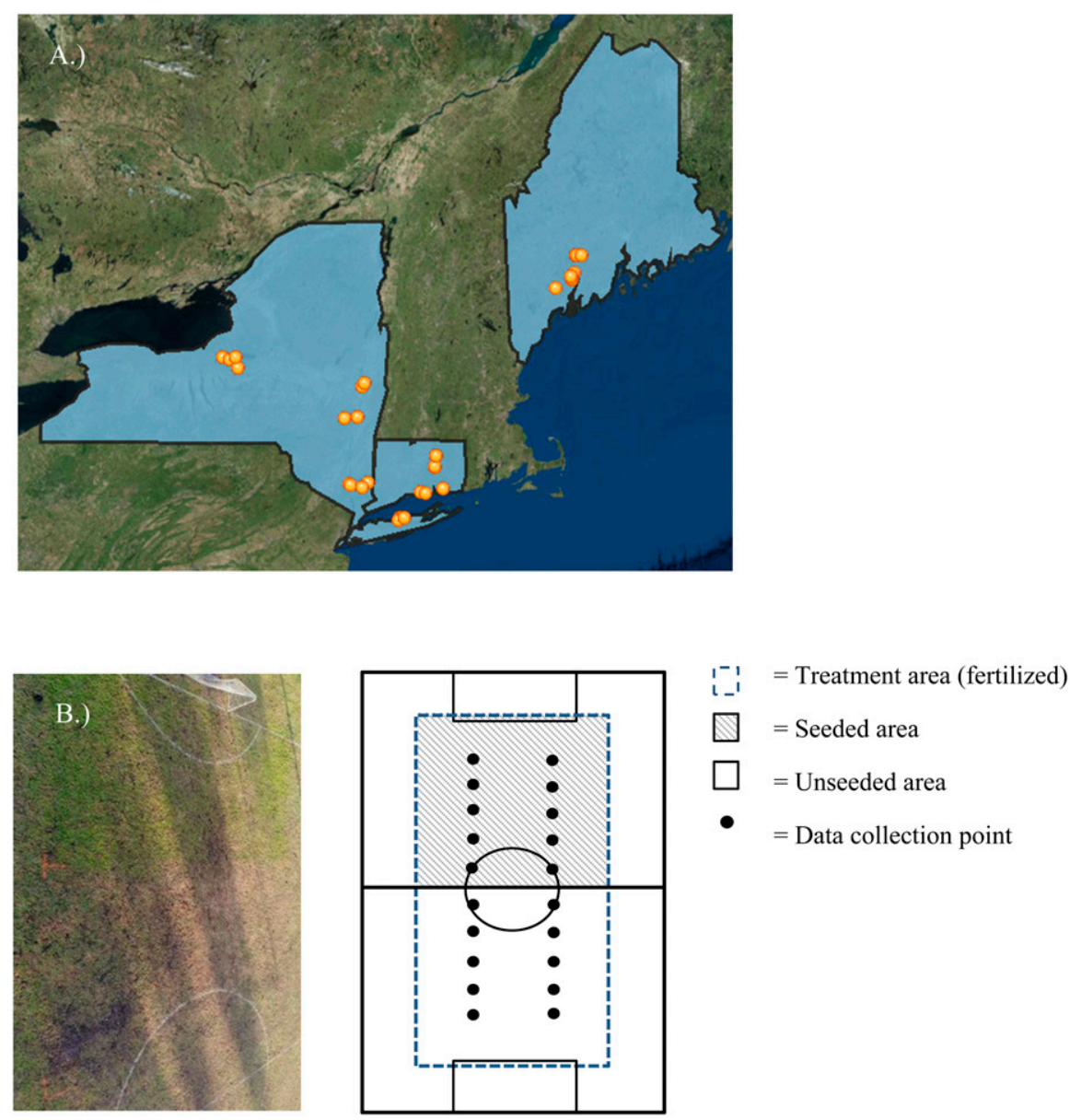

Fig. 1. A map of 22 school locations in both Central New York and the Northeast (New York, Connecticut, and Maine), where overseeding was studied on 48 fields over the 2014, 2015, and 2016 growing seasons (A). Most locations included multiple fields. Fields were overseeded with Lolium perenne on half of the field and not overseeded on the other half (B). The photo on the left shows half of a soccer field overseeded after $9 \mathrm{~d}$. Turf quality data were collected from 10 points on both sides of each field (schematic on the right) before and after overseeding. Figure not to scale.

Connecticut) (Fig. 1A). The research team comprised scientists and turfgrass/landscape educators from Cornell University, Cornell Cooperative Extension, New York Integrated Pest Management, the University of Connecticut, and Maine Department of Agriculture, Conservation, and Forestry; all of them identified school field managers willing to participate in this research. Clusters of fields were located in school districts identified by research team members to facilitate the distribution of materials for the project and supervise or perform data collection. All overseeding and fertilizer applications were performed by field managers at the selected locations and successfully incorporated into field maintenance schedules. The field managers were provided with the same fertilizer spreaders, seed, and fertilizer, which were donated by The Scotts Miracle Gro Company (Marysville, $\mathrm{OH}$ ). They also received training by our research team regarding application rates and calibration of equipment to ensure the same input and management across fields.

A subset (eight) of the 48 fields located in CNY were repetitively overseeded for 3 years, starting in Summer 2014. The remain- ing 40 sports fields were located across the Northeast at 22 different municipalities/ school districts in New York, Maine, and Connecticut. These Northeast fields were seeded for two seasons across 1 year, starting in Fall 2015. All participating schools were required to commit to following management protocols provided by the team of multistate researchers.

Half of each field was designated as the seeded/treated side, and the other half of the field was the unseeded/untreated control side. The seeded half was broadcast-seeded with a Lolium perenne blend (Scotts Miracle-Gro, Marysville, $\mathrm{OH})$ in the high-traffic central area of the field $(\approx 27 \mathrm{~m}$ wide and $55 \mathrm{~m}$ long), starting at midfield (Fig. 1B). Lolium perenne was used because previous studies had found the species to be an effective overseeding grass (Aamlid et al., 2012; Miller and Henderson, 2012). In 2014, the eight CNY fields were seeded weekly at $146 \mathrm{~kg} \cdot \mathrm{ha}^{-1}(3 \mathrm{lb}$ per $1000 \mathrm{ft}^{2}$ ) for 5 weeks between August and September This seeding rate was selected because previous studies had determined that this was an effective overseeding rate (Chinery et al., 2009; Elford et al., 2008; Harper et al., 2016). Between Aug. 2015 and 
Table 1. $P$ values of turf quality traits over time in response to repetitively overseeding half of a sports field at schools across Maine, Connecticut, and New York. Forty of the Northeast fields were overseeded in 2015 and 2016, and the eight Central New York fields were overseeded in 2014, 2015 , and 2016.

\begin{tabular}{|c|c|c|c|c|}
\hline & Change in turf trait & Seeding treatment & Time & Interaction term \\
\hline \multirow[t]{7}{*}{ Northeast fields } & Percent broadleaf weeds & $\mathbf{0 . 0 3}^{\mathrm{z}}$ & 0.79 & 0.48 \\
\hline & Percent bare ground & 0.36 & 0.70 & 0.66 \\
\hline & Greenness (DGCI) & 0.46 & 0.007 & 0.001 \\
\hline & Percent grass cover & 0.008 & 0.88 & 0.86 \\
\hline & Soil compaction & 0.19 & $<0.0001$ & 0.74 \\
\hline & Soil moisture & 0.53 & $<0.0001$ & 0.12 \\
\hline & Shear & 0.20 & $<0.0001$ & 0.48 \\
\hline \multirow[t]{6}{*}{ Central New York fields } & Percent broadleaf weeds & 0.32 & 0.61 & 0.40 \\
\hline & Percent bare ground & 0.16 & 0.009 & 0.85 \\
\hline & Greenness (DGCI) & 0.55 & 0.0009 & 0.58 \\
\hline & Percent grass cover & 0.15 & 0.27 & 0.62 \\
\hline & Soil compaction & 0.05 & 0.07 & 0.02 \\
\hline & Soil moisture & 0.88 & $<0.0001$ & 0.53 \\
\hline
\end{tabular}

${ }^{\mathrm{z}} P$ values of traits in bold are significantly affected by treatment $(P<0.05)$.

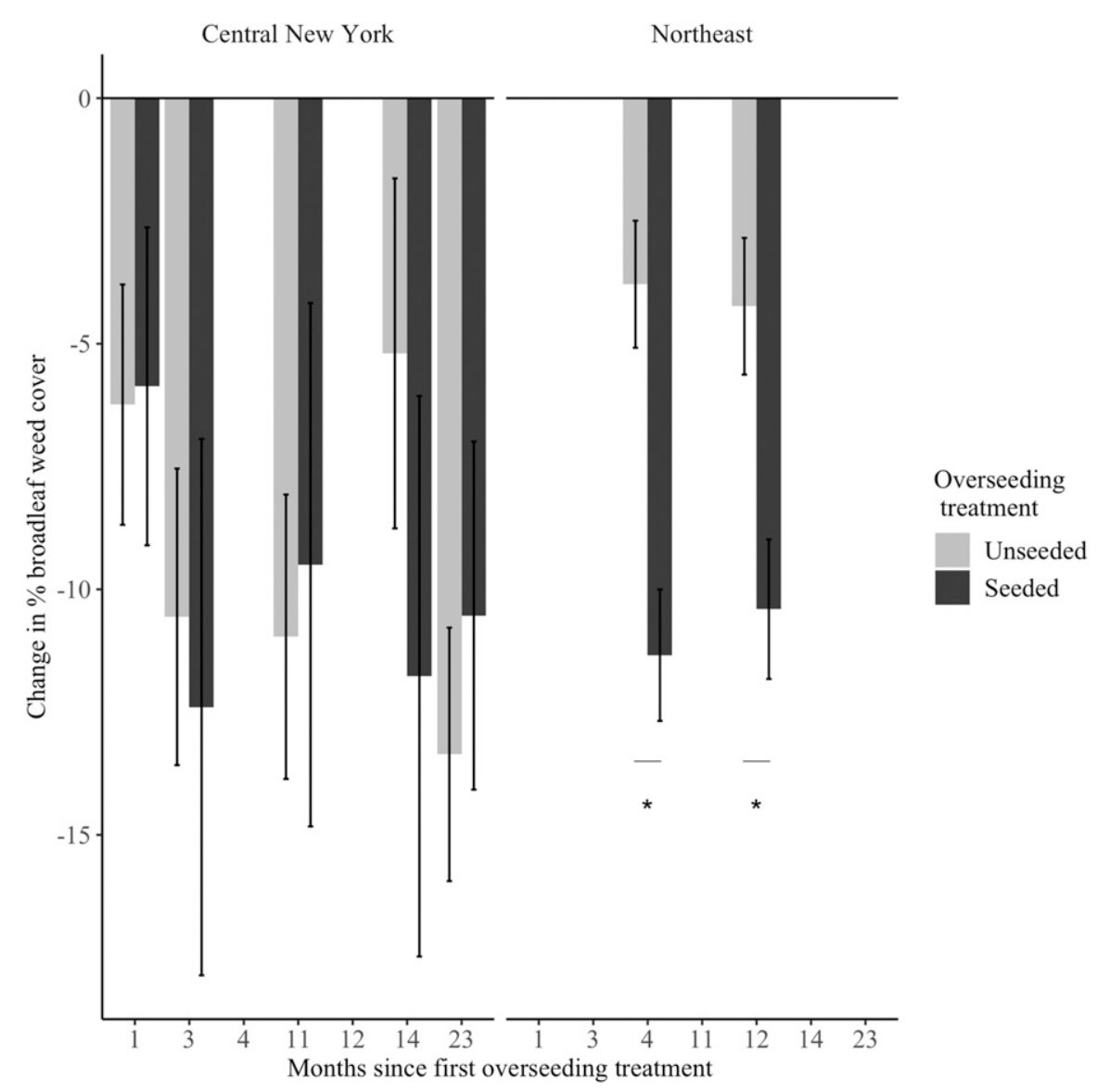

Fig. 2. Change in percent broad leaf weed cover from pretreatment conditions based on overseeding treatment in Central New York fields and Northeast fields. Statistically significant changes in percent broad leaf weed cover based on the overseeding treatment are marked with an asterisk * $(P<0.05)$. Statistical significance was calculated from an analysis of variance (ANOVA) of a linear mixed model with overseeding treatment, sample month, and their interaction as the fixed effects and field as the random effect. Post hoc analyses were conducted using Kenward-Roger degrees of freedom.

Nov. 2015, all 48 fields were seeded three times to make the process feasible for field managers to fit within their field maintenance schedules. The first overseeding application was $439 \mathrm{~kg} \cdot \mathrm{ha}^{-1}\left(9 \mathrm{lb}\right.$ per $\left.1000 \mathrm{ft}^{2}\right)$ to maintain the overall amount of seed applied; the next two applications were the regular 146 $\mathrm{kg} \cdot \mathrm{ha}^{-1}$ (3 lb per $1000 \mathrm{ft}^{2}$ ). Each of these applications was spaced 2 weeks apart. The same three overseeding treatments were repeated between Apr. 2016 and July 2016 at all 48 fields. Both halves of the field were fertilized once each year of the study with 48 $\mathrm{kg} \cdot \mathrm{ha}^{-1}\left(1 \mathrm{lb}\right.$ per $\left.1000 \mathrm{ft}^{2}\right)$ nitrogen $(\mathrm{N})$ using $26 \mathrm{~N}-0 \mathrm{P}-2 \mathrm{~K}$ fertilizer with $5.2 \%$ iron (Green Max; Scotts Miracle-Gro). Each participant was provided with a walk-behind broadcast spreader for seed and fertilizer applications. The research team inspected equipment and checked for proper calibration in situations involving participants who elected to use their own equipment.

Data collection. Measurements were collected at 10 points on each side of each field (seeded and unseeded). Two transects, $9 \mathrm{~m}$ apart, starting at $5 \mathrm{~m}$ from midfield in each direction were sampled every $6 \mathrm{~m}$ (Fig. 1B). At each of the 10 locations, seven variables were measured: percent broadleaf weed cover, percent turfgrass cover, percent bare ground, DGCI (a spectral reference measurement used as an indication of turf health and quality), percent soil moisture, depth to soil compaction zone, and turf shear strength. Turfgrass, weed, and bare groundcover were measured by placing a $1-\mathrm{m}$ square grid divided into twenty-five $0.20-\mathrm{m}^{2}$ squares with strings on the ground and either recording the turf cover at each string intersection point or recording the predominant turf cover within each square (different data collectors used different methods). The percent turf cover was calculated from the 16 intersections or the 25 squares. The DGCI was calculated using the Fieldscout GreenIndex App (Spectrum Technologies, Inc., Aurora, IL), which provides the percent green pixels from a photo of the turf. Soil moisture was calculated by taking an average of three readings from a FieldScout TDR 300 soil moisture probe (Spectrum Technologies, Inc.); the depth to soil compaction zone was measured with a penetrometer (AgraTronix Soil Compaction Tester, Streetsboro, $\mathrm{OH}$ ), which recorded the depth at which 300 psi of penetration resistance was reached (Duiker, 2002). Shear strength was calculated with a TSHEAR2-M Shear Strength Tester (TurfTec International, Tallahassee, FL) using the metal cleat attachment according to the standard protocol of stepping on the footplate, twisting the handle, and recording the torque value (Newton-meters) at the point at which the turf begins to tear. Shear strength was measured in 2015 and 2016. In 2014, field measurements were performed 1 week before the seeding treatments began, immediately after the 5-week treatment period, and again 8 weeks after the treatment period. In 2015 and 2016, measurements were performed 1 week before seeding treatments and again 2 weeks after the seeding treatments ended.

Data analysis. All data were analyzed using R version 3.3.3 (R Core Team, 2020). Statistical analyses of the change in each metric relative to the pretreatment level were performed. Broadleaf weed cover, total 


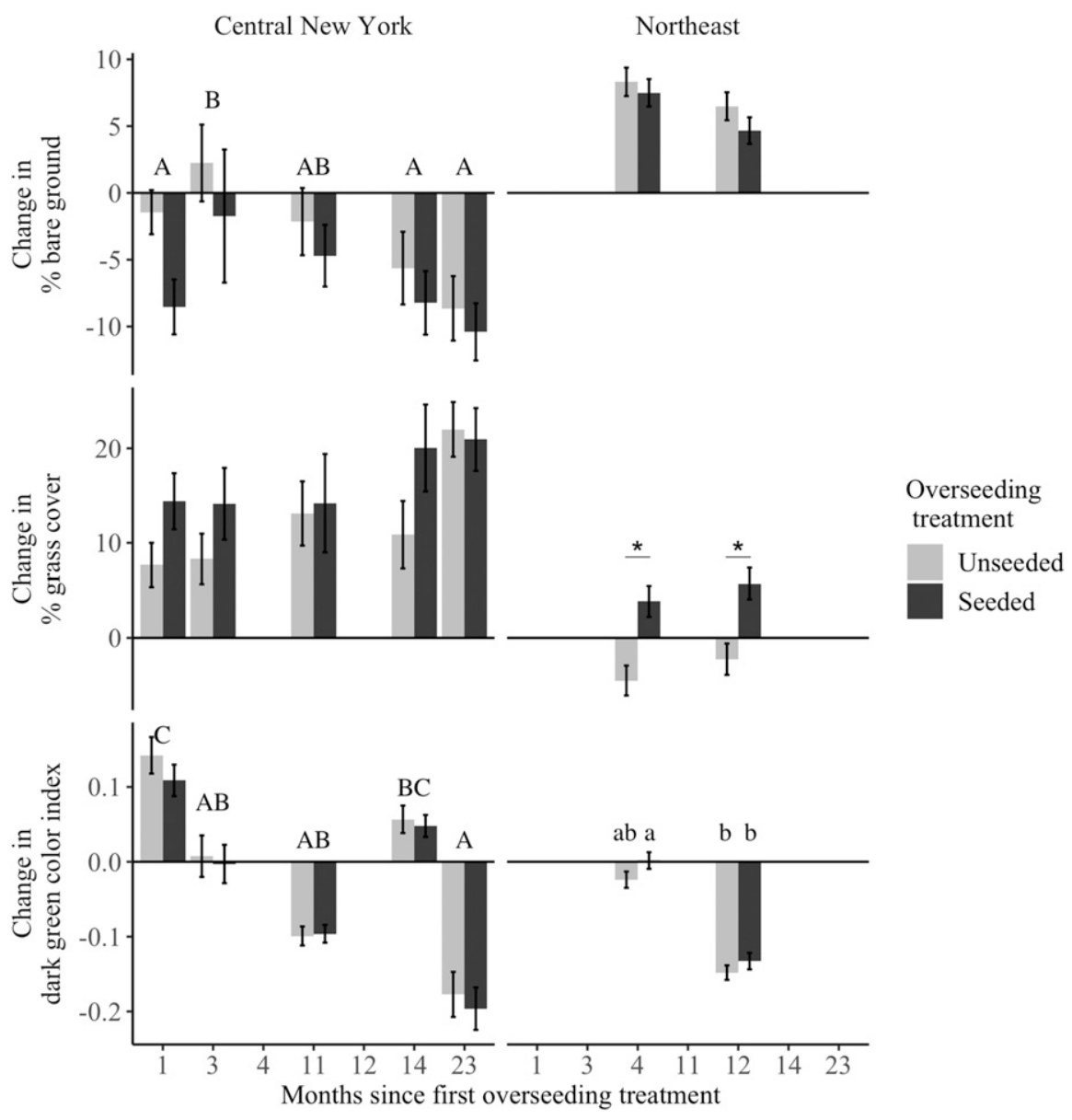

Fig. 3. Change in turf quality traits from pretreatment conditions based on overseeding treatment in Central New York and Northeast fields. Statistically significant changes in turf quality traits based on the overseeding treatment are marked with an asterisk * $(P<0.05)$. Bars with different capital letters have statistically different means at different months $(P<0.05)$, and bars with different lowercase letters have statistically different means at different months based on the overseeding treatment $(P<0.05)$ Statistical significance was calculated from an analysis of variance (ANOVA) of a linear mixed model with overseeding treatment, sample month, and their interaction as the fixed effects and field as the random effect. Post hoc analyses were conducted using Kenward-Roger degrees of freedom.

turfgrass cover, and bare groundcover were analyzed as the change in the percent cover. The DGCI, depth to compaction zone, shear strength, and soil moisture were analyzed as the change in percent greenness, centimeters to 300 psi, torque value in Newton-meters, and percent moisture, respectively.

All field data for the two sets of fields (CNY fields and Northeast fields) were analyzed separately using a generalized linear mixed model with overseeding treatment, time since beginning the first treatment, and their interaction as fixed effects (function lmer, in package lme4, version 1.1-13). Each individual field and its interactions with treatment and time were random effects. The dependent variables were the change in each metric relative to the pretreatment value as described previously. Two fields were eliminated from analysis in the CNY data set because data collection was incomplete on the first data collection day (CNY fields: $n=6$; Northeast fields: $n=40$ ). Assumptions of homogeneity of variance and normality of residuals were met. In some instances, residuals were outside the predicted range of inal field quality, and their interactions as fixed effects. Each individual field and its interactions with treatment, time, and quality remained as random effects, and post hoc estimated marginal means comparisons were performed using the Kenward-Roger correction for multiple means comparisons.

\section{Results}

Northeast: 40 fields with two seasons of applications. In the 40 Northeast fields, the overseeding treatment significantly impacted the change in percent broadleaf weed cover $(P=0.03)$; however, the change in percent broadleaf weed cover did not vary over time $(P=0.79)$ and the treatment $\times$ time interaction was not significant $(P=0.48)$ (Table 1 , Fig. 2). For both timepoints, the change in percent broadleaf weed cover was significantly higher in seeded plots (mean at 4 months, -11.34 and SE, 1.34 ; mean at 12 months, -10.40 and SE, 1.42) compared with unseeded plots (mean at 4 months, -3.79 and SE, 1.29; mean at 12 months, -4.24 and SE, 1.39) (Fig. 2).

The change in percent bare ground was unaffected by the overseeding treatment, over time, or treatment $\times$ time interaction (treatment, $P=0.36$; time, $P=0.70$; treatment $\times$ time, $P=0.66$ ) (Table 1, Fig. 3). However, the overseeding treatment had a significant effect on the change in percent grass cover $(P=0.008)$ (Table 1, Fig. 3), whereas time and the time $\times$ treatment interaction had no effect (time, $P=0.88$; treatment $\times$ time, $P=0.86$ ) (Table 1, Fig. 3 ). The change in percent turfgrass cover was significantly higher in treated overseeded plots (mean at 4 months, 3.85 and SE, 1.63; mean at 12 months: 5.72 and SE: 1.66$)$ compared with unseeded plots (mean at 4 months, -4.52 and SE, 1.58; mean at 12 months, -2.26 and SE, 1.66) for both time points. In contrast, overseeding had no effect on the DCGI $(P=$ $0.46)$; however, the DCGI was significantly different over time $(P=0.007)$ and for the treatment $\times$ time interaction $(P=0.001)$ (Table 1, Fig. 3).

Central New York: eight fields with three seasons of applications. The overseeding treatment and time did not affect the change in percent broadleaf weed cover in the CNY fields (treatment: $P=0.32$; time: $P=0.61$ ) (Table 1, Fig. 2). The treatment $\times$ time interaction also was not significant $(P=$ 0.40 ) (Table 1, Figure 2). The average changes in percent broadleaf weed cover were $-6.05,-11.48,-10.34,-8.48$, and -11.95 at months $1,3,11,14$, and 23 , respectively (Fig. 2).

The overseeding treatment had no effect on the change in percent bare ground, the change in percent total grass cover, and the change in the greenness index DGCI (bare ground, $P=0.16$; grass cover, $P=0.55$; DGCI, $P=0.15$ ) (Table 1, Fig. 3). However, time was significant for the change in percent bare ground and the change in DGCI (bare ground, $P=0.009$; DGCI, $P=0.0009$ ) (Table 1, Fig. 3). The change in percent bare 


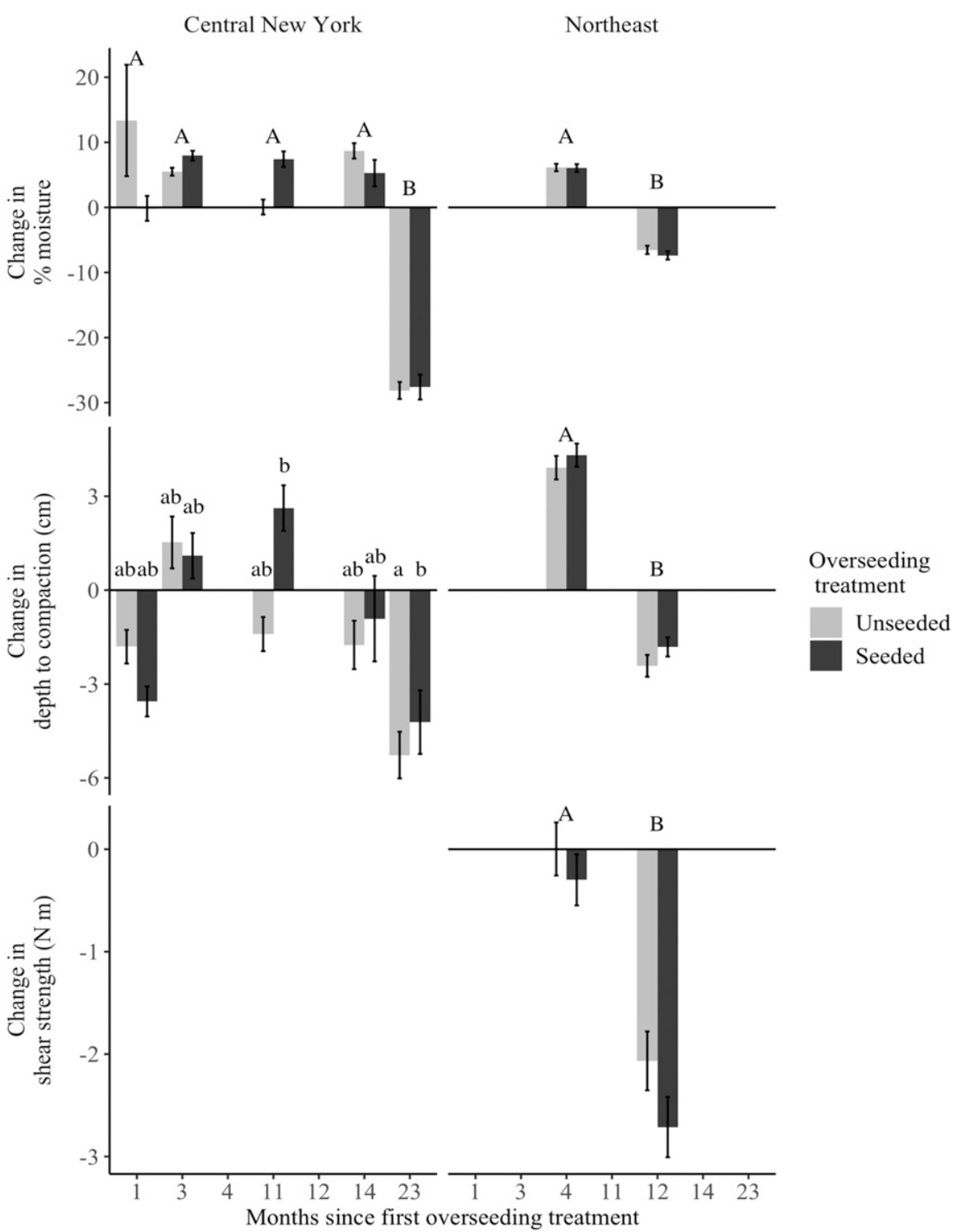

Fig. 4. Change in soil traits from pretreatment conditions based on overseeding treatment in Central New York fields and Northeast fields. Bars with different capital letters have statistically different means at different months $(P<0.05)$ and bars with different lowercase letters have statistically different means at different months based on the overseeding treatment $(P<0.05)$. Statistical significance was calculated from an analysis of variance (ANOVA) of a linear mixed model with overseeding treatment, sample month, and their interaction as the fixed effects and field as the random effect. Post hoc analyses were conducted using Kenward-Roger degrees of freedom.

ground was significantly higher at 3 months $(+0.25)$ compared with 1 month $(-4.99), 14$ months (-3.42), and 23 months (-9.52) (Fig. 3). The change in DGCI was significantly higher at 1 month $(0.13)$ compared with 3 months $(0.00), 11$ months $(-0.10)$, and 23 months $(-0.19)$, and it was significantly lower at 23 months $(-0.19)$ compared with 1 month (0.13) and 14 months (0.05) (Fig. 3). The treatment $\times$ time interaction was not significant for percent bare ground and DGCI (bare ground: $P=0.85$; DCGI: $P=0.58$ ) (Table 1, Fig. 3). Time and the treatment $x$ time interaction were not significant for the change in percent grass cover $(P=0.27$ and $P=0.62$, respectively) (Table 1 , Fig. 3).

The overseeding treatment had a significant effect on the change in depth to compaction in the CNY fields $(P=0.05)$ (Table 1 ,
Fig. 4). Although time was not significant for the change in depth to compaction, the treatment $\times$ time interaction was significant $(P=$ 0.02) (Table 1, Fig. 4). The change in depth to compaction was significantly lower in the treated overseeded plots (mean, -4.46 ; SE, $0.97)$ compared with unseeded plots at 23 months (mean, -1.85 ; se, 0.85) (Fig. 4). The overseeding treatment did not have an effect on the change in percent soil moisture; however, percent soil moisture was significantly lower at 23 months $(-15.37)$ compared with all other months $(1.86)$ in this study $(P<$ 0.0001) (Table 1, Fig. 4).

Correlation matrix of combined data sets. A Pearson correlation matrix summarizing all dependent variables across both sets of athletic fields (CNY and Northeast) showed significant correlations for all metrics ex- cept for percent moisture-percent broadleaf weeds and shear strength-percent broadleaf weeds $(r=-0.01$ and $P=0.64$ and $r=0.02$ and $P=0.29$, respectively) (Fig. 5). The strongest negative correlations were percent broadleaf weeds-percent grass cover $(r=$ $-0.74 ; P<0.0001)$ and percent bare ground-percent grass cover $(r=-0.55 ; P<$ $0.0001)$. The strongest positive correlations were percent moisture-DGCI $(r=0.46 ; P<$ $0.0001)$ and percent moisture-depth to compaction $(r=0.42 ; P<0.0001)$.

Change in broadleaf weeds based on original field conditions. The changes in percent broadleaf weeds for CNY and Northeast fields, respectively, were, on average, -42.44 and -66.61 for high-quality fields, -8.24 and -24.01 for mediumquality fields, and 1.77 and 7.96 for lowquality fields combining both seeded and unseeded plots (Fig. 6).

\section{Discussion}

The practice of overseeding a natural grass field repeatedly, or repetitive overseeding, can decrease populations of broadleaf weeds while increasing turfgrass cover, as demonstrated in the Northeast fields in this study, as stated in the first hypothesis. However, although the study was conducted for two seasons, our hypothesis that the efficacy of repetitive overseeding increases over time was not supported. Our second hypothesis regarding the additional improvements of repetitive overseeding for turfgrass and soil traits was partially supported, however. The greenness index, DGCI, and depth to compaction were impacted by the overseeding treatment $\times$ time interaction, but these changes may not signal a gradual improvement in turf over time. Soil traits were consistently affected by time, suggesting that environmental and/or field maintenance factors influenced these traits more than overseeding. Overall, changes in broadleaf weed populations, turf cover, and soil traits were variable, indicating that the location, season, maintenance routine, and year affect turf quality in general, as well as the efficacy of repetitive overseeding as a weed management practice on school athletic fields. These results are consistent with those of other studies that also found that field use and environmental factors were sometimes more predictive of turf traits than overseeding treatments (Harper et al., 2016; Larsen et al., 2004; Miller and Henderson, 2012).

Broadleaf weed cover and grass cover were highly negatively correlated, suggesting that overseeded Lolium perenne was able to outcompete broadleaf weeds. Bare ground and grass cover were less negatively correlated, suggesting that overseeded Lolium perenne showed limitations in establishing on bare ground. Our results indicate that repetitive overseeding should be considered a targeted management strategy to shift vegetation from broadleaf weeds to grass cover, but that it may be less effective for targeting or remediating bare ground unless aggressive 


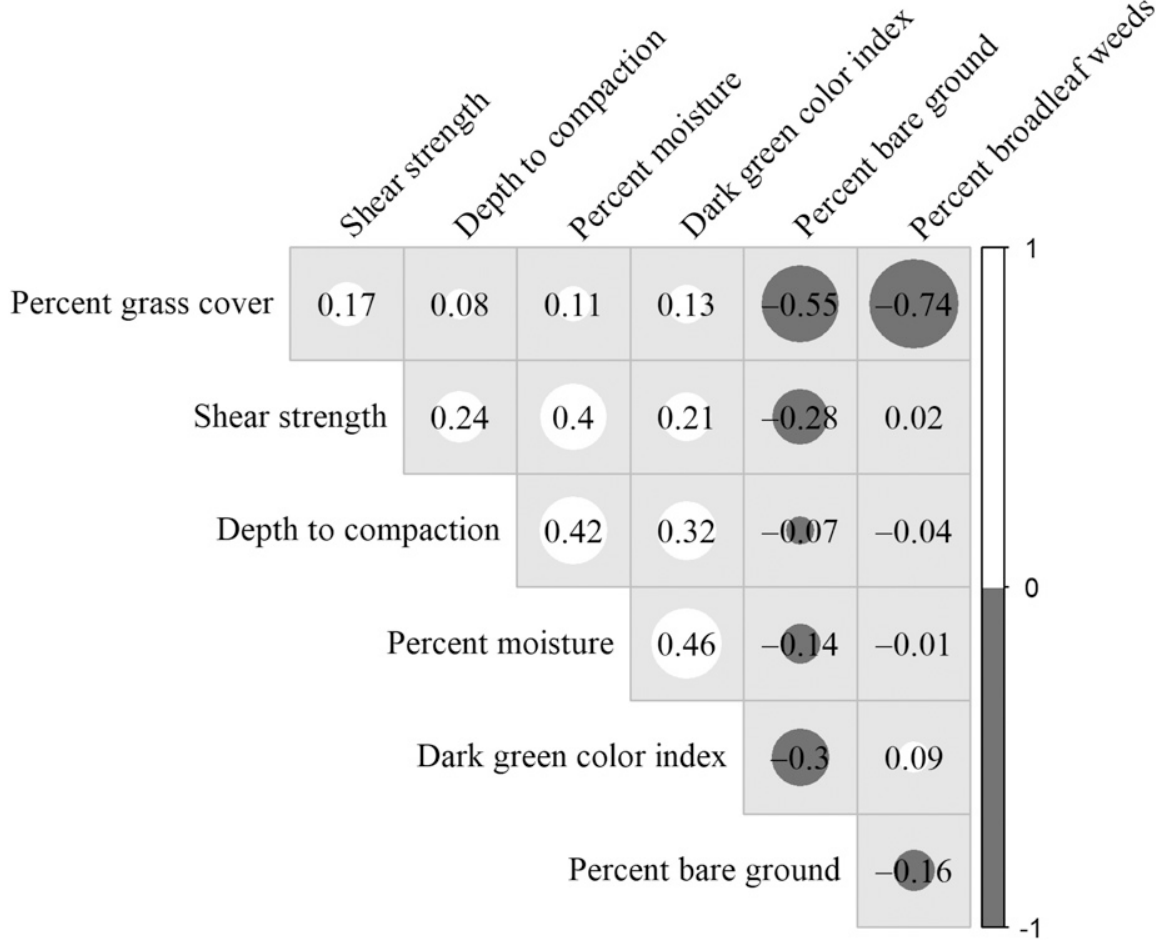

Fig. 5. Pearson correlation matrix of all dependent variables measured at all fields in Central New York and the Northeast across the treatment and sample period in both overseeded and unseeded field plots. Larger circles correspond to stronger correlations and the tone corresponds to whether the correlation is positive or negative.

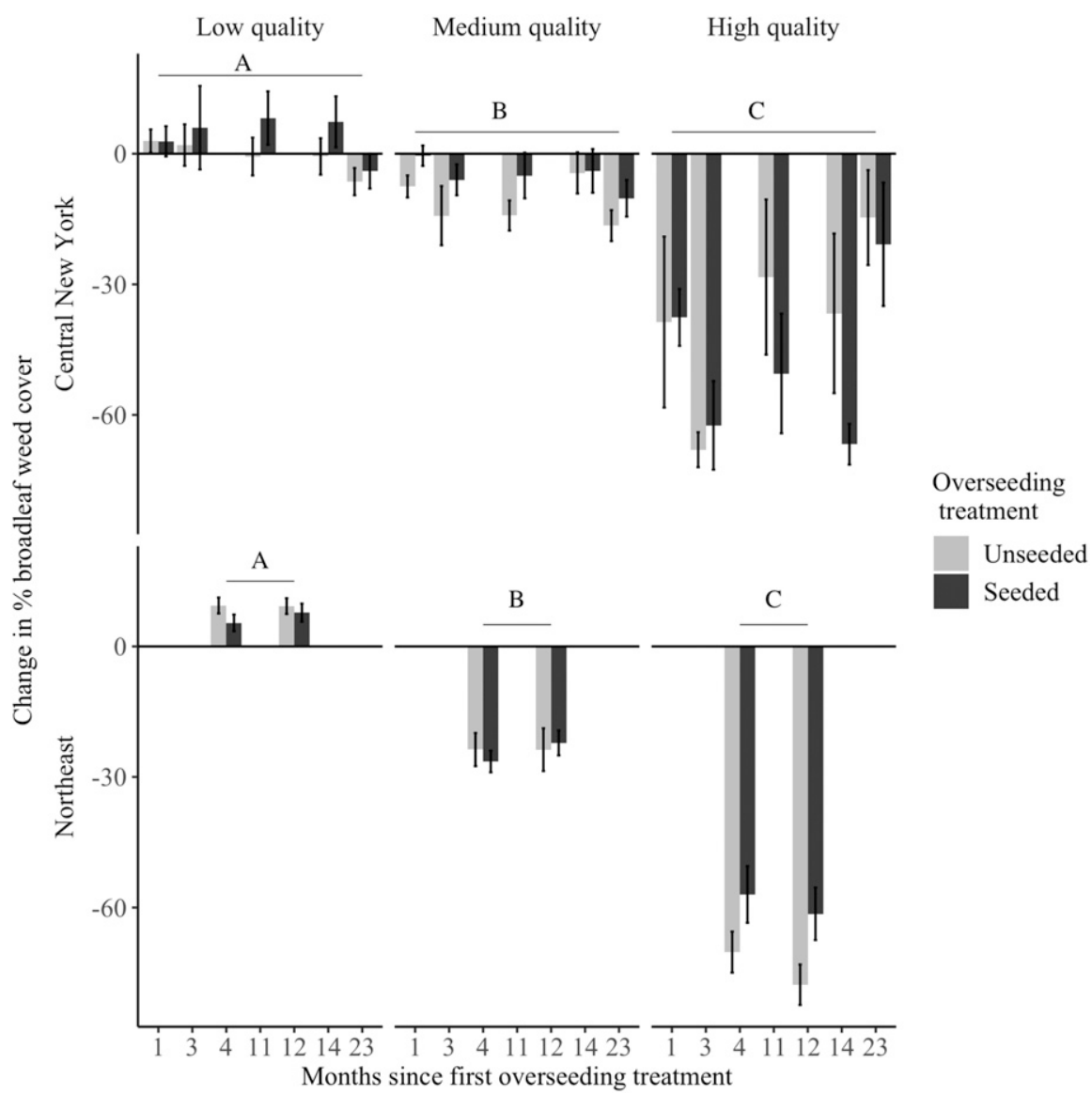

Fig. 6. Change in percent broadleaf weeds from pretreatment conditions based on overseeding treatment and original turf quality in Central New York fields and Northeast fields. Original turf quality was calculated based on the original percent grass cover before any treatments were applied. High-quality fields had $\geq 75 \%$ grass cover, medium quality fields had between $25 \%$ and $75 \%$ grass cover, and low-quality fields had $\leq 25 \%$ grass cover. techniques are used to ameliorate the heavy compaction and surface hardness of bare soil. The findings are consistent with those of Larsen et al. (2004), who reported that grass cover improved and broadleaf weed cover declined but that bare ground did not change in response to repetitive overseeding. Lolium perenne has a fast germination rate and high tillering rate (Christians et al., 2016; Hunt and Dunn, 1993; Laskey and Wakefield, 1978). These traits make Lolium perenne more competitive than other turfgrass species and many broadleaf weeds in the short term (Hunt and Dunn, 1993; Laskey and Wakefield, 1978). However, bare ground in natural turfgrass fields may be the result of excessive traffic, which causes too much stress and disturbance to support any plant growth (Grime, 1977). Excessive traffic can result in compaction, wear, and soil displacement; therefore, management strategies should focus on increasing cultivation, improving soil organic matter with the addition of topsoil or compost before reseeding, and managing play on heavily used fields through rotation rather than overseeding alone (Carrow and Petrovic, 1992; Taylor, 1981).

Weed species were not identified in this study to account for the variable resources and time commitments of collaborators, which limited our abilities to determine changes in weed cover over time. Additionally, grassy weeds were not distinguished from desired turfgrass species, which masked the impact of overseeding on weedy grass species over time. Although school playing field managers can maintain a turfgrass cover with any species mix of cool season turfgrasses, weedy grass species can be problematic. The different textures and colors of turf and weed species make playing surfaces less uniform and uneven (McCarthy and Murphy, 1994). Additionally, annual weeds thin strands of more desirable turfgrass species and create seasonal bare spots when they go dormant (Engel and Ilnicki, 1969). The annual Poa annua (annual bluegrass), for example, is problematic because it produces many seedheads while growing, thus reducing the uniformity of the playing surface (McCarthy and Murphy, 1994), and dies quickly in warm weather, leaving many bare spots in the turfgrass canopy (Engel and Ilnicki, 1969). Digitaria spp. (crabgrasses) and other annual grassy weeds germinate early in the spring and can dominate sections of a field by rooting at the nodes of prostrate stems. In the fall, the crabgrasses (Digitaria spp.) dieback, leaving behind open areas and thin turf (Engel and Ilnicki, 1969). This annual grassy weed presence may have had a role in the percent bare ground on our fields, although it was not measured in this study. Nonetheless, repetitive overseeding can be an effective strategy against Poa annua (Aamlid et al., 2012) and other annuals. Future overseeding studies should prioritize both grassy and broadleaf weed identification for a better assessment of the impacts of overseeding on specific species and their phenological development along with field use demands. 
Understanding how different weed management strategies affect specific weed species and how they change weed ecology generally will help field managers prioritize when they should invest resources in these overseeding strategies. For example, a field with intense demands for fall football play should target late summer and early fall for repetitive overseeding; however, for fields with intense spring lacrosse schedules and other spring season athletics, overwinter seeding could provide additional benefits to spring overseeding.

Environmental shifts may have also played a large role in variations in turf traits during this study. In May 2016, when overseeding treatments were being applied to all fields, large portions of the northeastern United States were experiencing a severe drought. New York, for example, experienced its ninth driest year on record in Fall 2016. This drought continued into June 2017, and it affected much of the region, with $53 \%$ of the Northeast experiencing an abnormally dry month (Northeast Regional Climate Center, 2017). Field managers in this study were asked not to irrigate their fields to reduce confounding factors in the experiment. The regional drought experienced in the northeastern United States in 2016 resulted in dry soil, which is reflected in our soil moisture measurements. Without water, turfgrass seeds were unable to germinate; therefore, they were unable to outcompete weed species. The importance of irrigation in the success of repetitive overseeding has been noted in other studies (Elford et al., 2008; Harper et al., 2016). The dry soil also led to very hard playing surfaces, which were reflected in our soil compaction measurements when the depth to 300 psi of resistance decreased in 2016. This high positive correlation between soil moisture and soil compaction is common (Filho et al., 2017). Therefore, the practice of overseeding as a weed management strategy and as a tool to improve turf quality should consider climate, soil moisture, and access to irrigation before being implemented.

The greenness index, DGCI, may have also been affected by the drought. DGCI is a spectral reference measurement used as an indicator of overall turf quality by quantifying green pixels. Many factors affect turf greenness, including plant density, plant health (Leinauer et al., 2014), mineral nutrition, and the dominant plant species that compose the turf, regardless of desirability (Miller and Henderson, 2012). We found that DGCI was affected by the interaction of overseeding and time. Overseeding may have improved turfgrass cover, increasing its greenness in 2015, but the drought may have extended dormancy in 2016, resulting in a decrease in DGCI that dwarfed any positive effects of overseeding.

Visualizing the change in percent broadleaf weed cover by original turf quality further highlights the difficulty of shifting the balance in weed competitiveness without changing other environmental and management factors. Regardless of overseeding treatments, fields with $25 \%$ or less grass cover before treatments had a slight increase in broadleaf weed cover. However, fields with $75 \%$ or more grass cover before treatments had a large decrease in broadleaf weed cover. The environmental or management factors that influenced the higherquality fields to continue developing greater grass coverage may also explain why the low-quality fields with thin grass cover proceeded to be populated by weed species.

Weed management in turf is tightly linked to creating the best environment for desirable turf species to grow; therefore, sound overall turf management protocols with proper mowing, irrigation, and fertilization are often the most effective weed management strategy (Busey 2003; Engel and Ilnicki, 1969; Hahn et al., 2020). Supplementation of turfgrass seed may only further enhance these highquality fields. Turfgrass species will be more competitive than many broadleaf weeds in mown fields because mowing repeatedly removes the apical meristem or flowers of broadleaf weeds while grass growth is stimulated (Fry and Huang, 2004). For example, mowing promotes tillering of grass species, thus increasing their density (Fry and Huang, 2004). However, mowing turfgrass too low can contribute to weed establishment and infestations because it reduces carbohydrate reserves and stresses the turfgrass ( $\mathrm{Abu}$ Dieyeh and Watson, 2006; Busey, 2003; Fry and Huang, 2004). Proper irrigation will also help with weed management. Too little water will prevent seed germination and growth, as we may have seen in our experiment, and too much water will encourage the growth of water-tolerant weeds such as annual bluegrass, nutsedges, and weeds that can spread by rooting at nodes, such as Digitaria spp. (crabgrasses) and Stellaria spp. (chickweeds) (Engel and Ilnicki, 1969). Too little fertilization can cause turfgrass species to grow slowly and leave ground open for weeds to emerge (Busey, 2003; DeBels et al., 2012; Johnson and Bowyer, 1982), but too much nutrition can cause weed species to proliferate if turfgrass species are struggling (Busey, 2003). There is some evidence that many grass species are more competitive than broadleaf plants at high rates of nitrogen fertilizer; however, some of the grass species that are most competitive, such as Poa annua (annual bluegrass), are undesirable; finding the correct balance of fertilization is also critical (Hahn et al., 2020). High-quality athletic fields with more turfgrass cover and fewer weeds may respond more effectively to overseeding compared with lower-quality fields with little turf and an abundance of weeds.

The economic reality of school budgets is also an important aspect of the sustainability of overseeding as a tool. Importantly, field managers in our study were able to successfully apply overseeding treatments within defined schedules, demonstrating the feasibility of incorporating this management strategy into their field maintenance schedules.
Therefore, we believe this is a feasible weed management tool for school grounds. However, repetitive overseeding did not consistently decrease weed cover to improve field aesthetics or safety over time for each field; therefore, it is not always the most effective method of weed control on school sports fields.

Overseeding can, within months, reduce weed populations and increase grass cover, but it is not the sole predictor of turfgrass weed pressure. Access to irrigation, especially in years of drought, is an important factor in its success; therefore, field managers without access to irrigation may find other management practices more beneficial in dry years. Additionally, some undesirable field traits, such as bare ground and compaction, may be the result of other environmental or management decisions, and overseeding alone will not remedy those issues. If a field is wellmanaged, then weed pressure is likely to be less of a concern regardless of overseeding treatment; if it is being poorly managed, then it is likely to increase. Overseeding may be an important weed management strategy in sports fields, especially where legislation prevents the use of other weed management tools. However, one strategy involving a pesticide-free or integrated pest management program should be used along with cultural practices such as cultivation, mowing, irrigation, and fertilization to improve overall turf quality and field safety.

\section{Literature Cited}

Aamlid, T.S, L. Nesheim, T. Pettersen, F. Enger, and P. Vesterbukt. 2012. Poa pratensis or Lolium perenne for establishment and overseeding of Scandinavian football (soccer) pitches. Acta Agriculturae Scandinavica, Section B - Soil \& Plant Sci. 62:32-43, doi: 10.1080/09064710.2012.685180.

Abu-Dieyeh, M. and A. Watson. 2006. Impact of mowing and weed control on broadleaf weed population dynamics in turf. J of Plant Interactions 4:239-252, doi: 10.1080/17429140601015226.

Alarcon, W.A., G.M. Calvert, J.M. Blondell, L.N. Mehler, J. Sievert, M. Propeck, D.S. Tibbetts, A. Becher, M. Lackovi, S.B. Soileau, R. Das, J. Beckman, D.P. Male, C.L. Thomsen, and M. Standbury. 2005. Acute illnesses associated with pesticide exposure at schools. JAMA 4:455-466, doi: 10.1001/jama.294.4.455.

Aldahir, P.C. and J.S. McElroy. 2014. A review of sports turf research techniques related to playability and safety standards. Agron. J. 106:12971308, doi: 10.2134/agronj13.0489.

Busey, P. 2003. Cultural management of weeds in turfgrass: A review. Crop Sci. 43:1899-1911, doi: $10.2135 /$ cropsci2003.1899.

Canadian Nursery Landscape Association. 2017. Pesticide regulations across Canada (federal, provincial, municipal): Urban Landscapes. Canadian Nursery Landscape Association, Milton, ON, Canada. 29 July 2020. <https://cnla.ca/learn/ pesticide-regulations-across-canada $>$.

Carrow, R.N. and A.M. Petrovic. 1992. Effects of traffic on turfgrass, p. 255-330. In: D.V. Waddington, R.N. Carrow, and R.C. Shearman (eds.). Turfgrass. Agron. Monograph No. 32 ASA, CSSA, and SSSA, Madison, WI. doi: 10.2134/agronmonogr32.c9.

Chinery, D. 2009. Heavy repetitive fall overseeding to improve low-input sports fields': A 
report to the New York State Turfgrass Association. Cornell Cooperative Extension, NY. 30 Aug. 2017. <http://www.ccerensselaer.org/ horticulture-program/Turfgrass-Research/FallOverseeding.aspx $>$.

Christians, N.E., A.J. Patton, and Q.D. Law. 2016. Fundamentals of turfgrass management. 5 th ed. Wiley, Hoboken, NJ.

Connecticut General Assembly. 2009. An act concerning pesticide applications at child day care centers and schools. Office of Legislative Management, Hartford, CT. 30 Aug. 2017.<https:// www.cga.ct.gov/2009/ACT/PA/2009PA-00056R00SB-01020-PA.htm>.

Dahl Jensen, A.M., O. Buhler, A. Kvalbein, and T.S. Aamlid. 2017. Evaluation of the occurrence of turfgrasses and weeds after repeated overseeding on fairways. Intl. Turfgrass Soc. Res. J. 13:389393, doi: 10.2134/itsrj2016.10.0837.

DeBels, B.T., S.E. Griffith, W.C. Kreuser, E.S. Melby, and D.J. Soldat. 2012. Evaluation of mowing height and fertilizer application rate on quality and weed abundance of five home lawn grasses. Weed Technol. 26:826-831, doi: 10.1614/ WT-D-12-00062.1.

Duiker, S.W. 2002. Diagnosing soil compaction using a penetrometer. Penn State Extension: Agronomy fact 63.

Elford, E.M.A., F.J. Tardif, D.E. Robinson, and E.M. Lyons. 2008. Effect of perennial ryegrass overseeding on weed suppression and sward composition. Weed Technol. 22:231-239, doi: 10.1614/WT-07-120.1.

Engel, R.E. and R.D. Ilnicki. 1969. Turf weeds and their control, p. 240-287. In: A.A. Hanson and F.V. Juska (eds.). Turfgrass science. Agron. Monograph No. 14 ASA, CSSA, and SSSA, Madison, WI.

Faustman, E.M., S.M. Silbernagel, R.A. Fenske, T.M. Burbacher, and R.A. Ponce. 2000. Mechanisms underlying children's susceptibility to environmental toxicants. Environ. Health Persp. 108:1321, doi: 10.1289\%2Fehp.00108s113.

Feldman, J. and L. Hepting. 2007. Ending pesticide dependency: The state of IPM. 12 May 2020. $<\mathrm{http}$ //www.beyondpesticides.org/assets/media/ documents/stateipm/stateipmreport/stateofipmlowres.pdf $>$.

Filho, A.M.S., C.L.B. da Silva, M.A.A. Oliveira, T.G. Pires, A.J. Alves, W.P. Calixto, and M.G. Narciso. 2017. Geoelectric method applied in correlation between physical characteristics and electrical properties of the soil. Trans. Environ. Electrical Eng. 2:37-44, doi: 10.22149/ teee.v2i2.85.

Fry, J. and B. Huang. 2004. Applied turfgrass science and physiology. Wiley, Hoboken, NJ.

Grime, J.P. 1977. Evidence for the existence of three primary strategies in plants and its relevance to ecological and evolutionary theory. Amer. Nat. 111:1169-1194, doi: 10.1086/283244.

Hahn, D., R. Sallenave, C. Pornaro, and B. Leinauer. 2020. Managing cool-season turfgrass without herbicides: Optimizing maintenance practices to control weeds. Crop Sci. 60:2204-2220, $<$ https://doi-org.proxy.library.cornell.edu/10.1002/ $\csc 2.20175>$.

Harper, R.W., W.R. Autio, J.T. Finn, and F.S. Rossi. 2016. Tree wardens and public grounds management in North America: Overseeding athletic fields with perennial ryegrass to promote safe playing surface. Arboric. J. 38:230 242, doi: 10.1080/03071375.2016.1243343.

Hunt, K.L. and J.H. Dunn. 1993. Compatibility of Kentucky Bluegrass and perennial ryegrass with tall fescue in transition zone turfgrass mixtures. Agron. J. 85:211-215, doi: 10.2134/ agronj1993.00021962008500020009x.

Johnson, B.J. and T.H. Bowyer. 1982. Management of herbicides and fertility levels on weeds and Kentucky Bluegrass turf. Agron. J. 74:845-850, doi: 10.2134/agronj1982.00021962007400050018xa.

Larsen, S.U., P. Kristoffersen, and J. Fischer. 2004. Turfgrass management and weed control without pesticides on football pitches in Denmark. Pest Manag. Sci. 60:579-587, doi: 10.1002/ ps. 845 .

Laskey, B.C. and R.C. Wakefield. 1978. Competitive effects of several grass species and weeds on the establishment of birdsfoot trefoil. Agron. J. 70:146-148, doi: 10.2134/agronj1978. 00021962007000010036x.
Leinauer, B., D.M. VanLeeuwen, M. Serena, M. Schiavon, and E. Sevostianova. 2014. Digital image analysis and spectral reflectance to determine turfgrass quality. Agron. J. 106:17871794, doi: 10.2134/agronj14.0088.

Legislative Assembly of Ontario. 2008. Bill 64, Cosmetic Pesticides Ban Act, Toronto, ON, Canada. 30 Aug. 2017. <http://www.ontla.on.ca/web/bills/ bills_detail.do?locale=en\&BillID=1967>.

McCarthy, L.B. and T.R. Murphy. 1994. Control of turfgrass weeds, p. 209-248. In: A.J. Turgeon (ed.). Turf weeds and their control. ASA, and CSSA, Madison, WI. doi: 10.2134/ turfweedsandtheircontrol1994.

Miller, N.A. and J.J. Henderson. 2012. Organic management practices on athletic fields: Part 1. The effects on color, quality, cover, and weed populations. Crop Sci. 52:890-903, doi: 10.2135/ cropsci2011.07.0359.

New York State Department of Environmental Conservation. 2010. Guidance on chapter 85 , Laws of 2010: Summary of pesticide prohibition requirements and pesticide alternatives regarding schools and day care centers in New York State. Dec. 22, 2010, Albany, NY. 30 Aug. 2017. <http://www.dec.ny.gov/ docs/materials_minerals_pdf/guidancech85. pdf $>$.

Northeast Regional Climate Center. 2017. Northeast Overview, Bradfield Hall, Cornell University, Ithaca, NY. 1 Nov. 2017. <http://www.nrcc. cornell.edu/regional/narrative/narrative.html $>$.

R Core Team. 2020. R: A language and environment for statistical computing. R Foundation for Statistical Computing, Vienna, Austria. $<$ http://www.R-project.org/>.

Taylor, D. 1981. Turf management on athletic fields. Ag. Ext. Service, U. of Minn. Hort. fact sheet No. 53.

Waddington, D., A. McNitt, and P. Landschoot. 1997. Constructing and maintaining safe playing surfaces, p. 107-113. In: E. Hoerner and F. Cosgrove (eds.). International symposium on safety in baseball/softball. ASTM International, West Conshohocken, PA. doi: 10.1520/ STP11871S. 